\title{
El papel del Congreso Local Estudiantil en las iniciativas de unidad latinoamericana del Constitucionalismo (1916-1918)
}

The role of the Local Student Congress in the initiatives for the Latin American unity of the Constitutionalism (1916-1918)

\section{David Antonio Pulido Garcia*}

RESUMEN: Durante el gobierno de Venustiano Carranza se adelantó una iniciativa diplomática y a la vez intelectual para Latinoamérica, que consistía en nombrar como pensionados estudiantiles a destacados jóvenes universitarios en las legaciones mexicanas de cinco países suramericanos (Argentina, Brasil, Chile, Uruguay y Colombia), con el fin de fomentar el diálogo e intercambio culturales entre ellos y los jóvenes intelectuales universitarios de los países que los recibían. El objetivo del presente artículo es reconstruir la forma en que esta iniciativa se gestó y se puso en marcha, planteando la hipótesis de que dicha iniciativa constituyó parte importante de la política de unidad latinoamericana adelantada por el gobierno constitucionalista, hipótesis que será verificada a lo largo del texto.

Palabras Clave: Latinoamérica, Constitucionalismo, Intelectuales, Movimiento estudiantil.

ABSTRACT: A diplomatic and intellectual initiative for Latin America was conceived by Venustiano Carranza's government. It involved the designation of some prominent university students as grant holders in Mexican legations in five South American countries (Argentina, Uruguay, Chile, Brazil and Colombia). This program was aimed at promoting dialogue and cultural exchange between young Mexican intellectuals and those from the countries that hosted them. This article is intended to look into the way this initiative was conceived and launched. The hypothesis is that this effort was an important part of the policy created by the constitutionalist government, intended to reach Latin American integration.

KEY wORDS: Latin America, Constitutionalism, Intellectuals, Student movement.

10.22201/cialc.24486914e.2017.65.56898

Fecha de recepción: 7 de marzo, 2017

Fecha de aceptación: 31 de julio, 2017

Posgrado en Historia, Facultad de Filosofía y Letras-unam (dapulidoga@yahoo.com.co). 


\section{INTRODUCCIÓN}

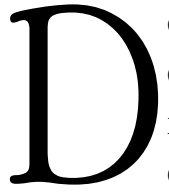

entro de la historiografía mexicana se ha documentado que durante el gobierno de Venustiano Carranza se adelantó una iniciativa diplomática y a la vez intelectual para Latinoamérica que consistía en nombrar como pensionados estudiantiles ${ }^{1}$ a destacados jóvenes universitarios en las legaciones mexicanas de cinco países suramericanos (Argentina, Brasil, Chile, Uruguay y Colombia), con el fin de fomentar el diálogo e intercambio culturales entre ellos y los jóvenes intelectuales ${ }^{2}$ universitarios de los países que los recibían, obedeciendo así a la entusiasta campaña del Estado mexicano, encaminada a mejorar la imagen que del país se tenía en el resto de Latinoamérica, una vez terminado el periodo más violento de la Revolución.

No obstante, en la mayoría de trabajos que indagan sobre la gestión diplomática del gobierno de Venustiano Carranza y/o por su relación con los estudiantes e intelectuales de la época, la iniciativa de enviar estudiantes sobresalientes como parte de las legaciones mexicanas en el sur del continente no pasa de tener un cariz casi anecdótico, pues se menciona breve-

1 “[... ] su misión no es [...] servir en calidad de agregados a las legaciones que nuestro gobierno tiene en Sud-América, ni desempeñar una misión diplomática", todo lo contrario, "en su calidad de pensionados, los estudiantes elegidos no tienen más obligaciones que estudiar y hacer labor de acercamiento entre México y las Repúblicas Latino-americanas". Véase "Fueron elegidos los estudiantes que van a Sudamerica", en El Universal, México, 12 de septiembre, 1918, p. 1.

2 La categoría jóvenes intelectuales se abordará en este artículo para referirse a los cuadros dirigentes (políticos e ideológicos), de las diferentes organizaciones estudiantiles analizadas. Se recurre a ella para hacer énfasis en que, durante el periodo estudiado, dichos intelectuales se encontraban en un proceso de formación del cual, si bien son conscientes, aún ignoran sus resultados, hecho que sin duda los diferencia de los intelectuales ya consolidados. Este punto hace que el uso de la categoría jóvenes intelectuales esté muy cercano a los planteamientos de Pierre Bourdieu, quien afirma que al interior del campo intelectual los intelectuales se diferencian de acuerdo a su posición frente al poder, de tal forma que se pueden dividir en intelectuales dominantes y aspirantes o entre establecidos y recién llegados. Su posición frente al poder depende del prestigio, autoridad, reconocimiento social y principalmente del "capital intelectual" que detenten y de la identificación de éste con la "cultura legitima". Pierre Bourdieu, Intelectuales, política y poder, Buenos Aires, Eudeba, 1999. 
mente como uno más de los múltiples ejemplos que ilustran la importancia que el Estado mexicano le brindó a la solidificación de sus relaciones internacionales a finales de la segunda década del siglo Xx. En ese sentido, este artículo pretende llenar este vacío historiográfico, en la medida en que busca reconstruir detalladamente la génesis de esta importante iniciativa diplomático-intelectual.

\section{LA JUVENTUD ES LA ESPERANZA DE LA PATRIA}

"Yo debo ser el primer revolucionario que caiga, y ustedes, los jóvenes, los que deben substituirme."” Estas fueron las palabras con las que el Primer Jefe del ejército constitucionalista Venustiano Carranza correspondió a la multitudinaria manifestación estudiantil que se concentró frente a Palacio Nacional la tarde del 27 de junio de 1916, con el fin de demostrar la voluntaria adhesión y respaldo incondicional de la juventud capitalina al gobierno constitucionalista, a propósito de la reciente irrupción del ejército estadounidense en territorio mexicano, conocida historiográficamente como la Expedición punitiva. ${ }^{4}$ Sin embargo, tanto las manifestaciones como la alocución presidencial no fueron situaciones fortuitas y por lo tanto no pueden explicarse nada más por la exaltación coyuntural de un nacionalismo lesionado por la intromisión del ejército extranjero. Todo lo contrario, para rastrear cómo se formaron las condiciones que posibilitaron estas intervenciones, es necesario indagar sobre la política seguida por el gobierno constitucionalista en lo que respecta a los estudiantes y a su organización gremial, sin perder de vista la forma en que la comunidad estudiantil recibió, participó e incluso influyó en dichas políticas.

3 "Yo debo ser el primer revolucionario que caiga", en El Pueblo, México, 28 de junio, 1916, p. 1.

4 Sobre el tema se consultó: Alberto Salinas Carranza, La expedición punitiva, México, Botas, 1937; Isidro Fabela [ed.], Documentos históricos de la Revolución mexicana, México, Cámara de Senadores, LXI Legislatura/Universidad Autónoma Metropolitana, 2010. 
La ocupación definitiva de la capital por parte del ejército constitucionalista, en agosto de 1915, supuso una suerte de alivio para los habitantes de la Ciudad de México, en la medida en que la mayoría comprendió, especialmente las clases medias, que la llegada al poder del general Venustiano Carranza representaba el inicio de una nueva etapa de estabilidad política que no podía ser brindada por ninguna de las demás fuerzas en contienda, caracterizadas por sus reivindicaciones estrechamente locales en lo social y por su creciente radicalidad en lo político. ${ }^{5}$ Por otro lado, la Ciudad de México con la que se encontró el gobierno constitucionalista distaba mucho de ser la pujante metrópoli que era antes de 1910. Entre las epidemias de tifo, gripa y tuberculosis, ${ }^{6}$ sobrevivía una sociedad atemorizada y envuelta en una vida política signada por la incertidumbre, así como un ambiente cultural y estudiantil que penosamente alcanzaba a mantenerse activo en medio de aquella debacle. ${ }^{7}$ En su mayoría, quienes intentaban mantener a flote las propuestas académicas y culturales en la Ciudad de México eran jóvenes integrantes de las familias de clase media, varias de ellas venidas de provincia, que después del estallido de la Revolución ocuparon el lugar que antes pertenecía a las familias cercanas al régimen de Porfirio Díaz. ${ }^{8}$ Jóvenes de clase media que no habían encontrado, en tiempos de la Revolución, un lugar estable de usufructo económico desde lo profesional y mucho menos un espacio real de participación política, hasta la llegada del constitucionalismo al poder, ya que ninguno de los gobiernos que le antecedieron, ni el de Madero ni el de Huerta, había desmontado efectivamente el aparato político-administrativo del porfiriato. ${ }^{9}$ En pocas palabras, "La simpatía y el apoyo que los universitarios otorgaron a Carranza desde

5 Javier Garciadiego y Sandra Kuntz Ficker, "La Revolución mexicana”, en Nueva Historia general de México, México, El Colegio de México, 2014, pp. 537-594.

6 El Pueblo, México, 6 de enero, 1916, p. 3.

Morelos Torres Aguilar, Cultura y revolución. La universidad popular mexicana (Ciudad de México 1912-1920), México, unam, 2009, p. 374.

8 Jean Meyer, La Revolución mexicana, México, Tusquets, 2004, p. 123.

9 Charles Cumberland, La Revolución mexicana. Los años constitucionalistas, MéxiCO, FCE, 1980, p. 63; Luis Barrón, Carranza el último reformista porfiriano, México, Tusquets, 2009, pp. 173-213; Pedro González Blanco, De Porfirio Díaz a Carranza, México, Gobierno del Estado de Tabasco, Consejo Editorial, 1980. 
1916 se debieron, básicamente, a que impuso orden en la capital, a que era la única posibilidad de gobierno moderado y, sobre todo, a que estaba claro que su aparato político se encontraba abierto a todos aquellos - profesores y estudiantes-que quisieran colaborar con él". ${ }^{10}$

Carranza, consciente de las complejas relaciones que sus antecesores habían establecido con la universidad y con el movimiento estudiantil, sabía que una política acertada al respecto podía granjearle un consenso político estable al interior de las clases medias, no sólo en la capital sino en varios lugares de la República donde ya existían movilizaciones estudiantiles desde tiempos del maderismo. Lo mismo ocurría del lado de los estudiantes. Si bien la comunidad estudiantil activa a principio de 1916 distaba mucho de ser aquella que se opuso vehemente a Madero ${ }^{11}$ y había recibido, pasiva pero complacientemente, el advenimiento de Huerta, ${ }^{12}$ para nada era ajena a la importancia de su papel en la estabilidad política, sobre todo en la capital del país. ${ }^{13}$ Muestra de ello fue la permanente existencia, desde el Primer Congreso Nacional de Estudiantes en 1910, de una movilización estudiantil capitalina que se cristalizó en la creación, a finales de 1915, del Congreso Local Estudiantil del Distrito Federal (CLEDF), ${ }^{14}$ agremiación que significaba de las pocas iniciativas estudiantiles vigentes que intentaron mantener cierto dinamismo en la vida cultural y estudiantil de la Ciudad de México.

Es por esta razón, y por el mutuo conocimiento de los beneficios que podría traer una posible alianza entre los estudiantes y el gobierno, que a los pocos meses de haberse asentado el constitucionalismo en la capital, por iniciativa del estudiante Gabino Palma, en aquel entonces presidente

10 Javier Garciadiego, Rudos contra cientificos. La universidad nacional durante la Revolución mexicana, México, El Colegio de México/unam, 2000, p. 320.

11 Walter Astié-Burgos, Encuentros y desencuentros entre México y los Estados Unidos en el siglo XX. Del Porfiriato a la posguerra fría, México, Porrúa, 2007, p. 82; Charles Cumberland, Madero y la Revolución mexicana, México, Siglo XxI, 1984.

12 Diego Arenas Guzmán, El régimen del general Huerta en proyección histórica, México, INEHRM, 1970.

13 Garciadiego, Rudos contra científicos..., p. 321.

14 Lourdes Velázquez Albo, Los Congresos nacionales universitarios y los gobiernos de la Revolución 1910-1933, México, IISUE-UnAm/Plaza y Valdés, 2007, p. 35. 
del CLEDF, se reunieron en la capital los representantes de las principales agremiaciones estudiantiles de la República ${ }^{15}$ con el fin de iniciar los trabajos preparativos del Segundo Congreso Nacional de Estudiantes (IICNE), reunión que, según el diario El Pueblo, estaría patrocinada por el jefe del poder ejecutivo de la Nación. ${ }^{16}$ Tal patrocinio, como era de esperarse, fue correspondido por los estudiantes con similares muestras públicas de simpatía, como lo fue la convocatoria a los estudiantes de la capital para iniciar una gran colecta monetaria con el fin de "contribuir a la amortización de la deuda interior de México", ${ }^{17}$ lanzada por el comité iniciador de la segunda asamblea general del CLEDF. ${ }^{18}$

Ahora bien, para el sector estudiantil era claro que a causa del difícil momento político y diplomático por el que atravesaba el país, debido a la intromisión territorial del general Pershing, el apoyo que se le pudiera otorgar al gobierno constitucionalista no se jugaba únicamente en el ámbito estrictamente local y financiero. De tal suerte que las muestras de apoyo a las instituciones por parte de los estudiantes empezaron a circular en los diarios, bajo enardecidas arengas patrióticas que dejaban muy en claro la importancia que, en especial los cuadros del movimiento estudiantil, le otorgaban al momento histórico por el que atravesaban. Jorge

15 Agustín F. Vidales asistió en representación del Centro Liberal de Estudiantes de Puebla, Jorge Ávila asistió por la Asociación de Estudiantes de jurisprudencia, David Vilchis Espinosa asistió por el Centro Liberal, Eduardo Guerra asistió por la Comisión Auxiliar del Comité Organizador de Estudiantes y José González por la Liga de Estudiantes de Querétaro. "Convocatoria a todos los estudiantes de la capital", en $E l$ Demócrata, México, 4 de mayo, 1916, p. 2.

16 "Trabajos preparativos para celebrar el Congreso Nacional de Estudiantes", en El Pueblo, México, 26 de abril, 1916, p. 1.

17 "Convocatoria a todos los estudiantes de la capital", en El Demócrata, México, 4 de mayo 1916, p. 2.

18 "Reúnense en una sesión los estudiantes", en El Demócrata, México, 8 de mayo, 1916, p. 1.; "Ayer se efectuó la primera sesión del Congreso Local de Estudiantes", en El Pueblo, México, 22 de mayo, 1916, p. 1. La asamblea estaba integrada, entre otros, por Jorge Prieto Laurens y Miguel Torner, en cuya reunión, aparte de la ya mentada iniciativa económica, se eligió la mesa directiva del CLEDF para aquel año, en la que fueron designados correspondientemente como Presidente y segundo Secretario los dos estudiantes antes mencionados. 
Prieto Laurens firmó una de aquellas arengas en el siguiente tono: "iPatria, si la cruenta lucha por tu Soberanía e integridad se avecina, listos estamos a sacrificarnos en tu defensa! hemos exclamado todos ante el peligro."19 Tal fue la posición secundada por los estudiantes de la Escuela Práctica de Ingenieros quienes, en "memorial destinado al Primer Jefe del Ejército Constitucionalista", manifestaban la intención de "presentar su contingente, en el caso de una guerra internacional", solicitando que entre tanto se les autorizara para que "en los talleres de la Escuela" fabricaran, decían ellos, "implementos de guerra relacionados con nuestra profesión". ${ }^{20}$

Aunque patrióticas y bienintencionadas, las peticiones guerreristas de los estudiantes no dejaban de ser un despropósito. Entrar en guerra con Estados Unidos a pocos meses de haber alcanzado cierta estabilidad política con la llegada del constitucionalismo al poder, representaba un suicidio político, y de ello estaba plenamente consciente Carranza quien, desde el momento en que conoció sobre los hechos de Columbus, intentó tratar el asunto por canales estrictamente diplomáticos, sin que ello haya significado que no hubo movilización militar y en ocasiones escaramuzas furtivas entre los dos ejércitos. ${ }^{21}$

Luis Cabrera, uno de los ideólogos más importantes del constitucionalismo, recordaría en los siguientes términos la actitud de Carranza en aquellos momentos: "Carranza se armó de las únicas armas que no necesitaba importar de Estados Unidos: de patriotismo, de entereza y de prudencia, y se preparó a la única lucha posible: la del derecho inerme contra la injusticia armada." ${ }^{22}$ Sin embargo, lejos de ser una política pasiva y estoica basada en la defensa de un "derecho inerme", la de Carranza fue una política dinámica que, ante la imposibilidad del éxito de una movilización armada, se desarrolló de preferencia en el ámbito ideológico, no

19 "A los estudiantes y a la juventud en general", en El Pueblo, México, 1º de junio, 1916, p. 3 .

20 "Los alumnos de la EPI ofrecen sus servicios al gobierno", en El Pueblo, México, 10 de junio, 1916, p. 2.

${ }^{21}$ Luis Cabrera, La herencia de Carranza, México, INHERM, 2015, p. 83.

${ }^{22}$ Ibid., p. 83. 
sólo de México, sino del continente en general, en la que el movimiento estudiantil jugó un papel fundamental.

Desde mediados de 1914 las naciones latinoamericanos habían expresado su preocupación por las tensas relaciones entre México y Estados Unidos a propósito de la ocupación de Veracruz por el ejército estadounidense. En aquella ocasión Argentina, Brasil y Chile habían ofrecido sus buenos oficios para llegar a una solución pacífica del problema, facilitando el entendimiento entre las fuerzas huertistas, constitucionalistas y el gobierno de Estados Unidos. No obstante, y pese a las ventajas que hubiera podido obtener de aquel ofrecimiento, Carranza optó por no participar y dejar por sentado que no estaría dispuesto a tratar asuntos de política interior de México con ninguna otra nación. Lo propio hizo un año después cuando, por iniciativa del Departamento de Estado de Washington, Argentina, Brasil, Chile, Bolivia, Uruguay y Guatemala firmaron una invitación colectiva a todas las facciones rebeldes de México para entablar un diálogo con vistas a la superación del conflicto interno mexicano. ${ }^{23}$ En aquella ocasión, Carranza fue mucho más elocuente: "Como Primer Jefe del Ejército Constitucionalista, encargado del Poder Ejecutivo de la República, no puedo consentir en que los asuntos interiores de la misma se traten por mediación, ni por iniciativa siquiera, de ningún gobierno extranjero, puesto que todos tienen el deber, ineludible, de respetar la soberanía de las naciones."24

No obstante el tono categórico de sus declaraciones, las posiciones de Carranza eran vistas con gran admiración entre los diplomáticos latinoamericanos, por lo que no es de extrañarse que la incursión del general Pershing a territorio mexicano haya sido rápidamente censurada por diferentes diarios latinoamericanos que hacían eco de sus respectivas posiciones diplomáticas. ${ }^{25}$

23 Un detallado trabajo de la política internacional de Carranza se encuentra en Eduardo Luquin, La política internacional de la revolución constitucionalista, México, INEHRM, 1957.

24 Cabrera, op. cit., p. 89.

25 "La opinión en las naciones latinas", en El Demócrata, México, 27 de mayo, 1916, p. 1. 
Por ello, la ocasión se presentaba favorable para que desde México se apelara a la solidaridad internacional en busca de algún tipo de apoyo que lo sostuviese en tan difícil escenario diplomático. Así lo comprendieron los intelectuales más cercanos al régimen de Carranza, quienes a través de las páginas del diario El Pueblo se dieron a la tarea de llenar de contenido ideológico su política de acercamiento con las naciones latinas del continente. ${ }^{26}$ Una de las primeras iniciativas a este respecto fue la declaración como día nacional en México de la fiesta de la Independencia de Argentina a través de un acto legislativo, la cual fue reseñada por el diario capitalino

${ }^{26}$ Es de resaltar que no existe un estudio específico sobre la construcción ideológica del discurso latinoamericanista de El Pueblo durante la etapa constitucionalista. No obstante, en la revisión hemerográfica que se ha realizado para la redacción de este artículo se han podido determinar algunas características de la labor ideológica que en este sentido emprendieron importantes intelectuales constitucionalistas en el mencionado diario, dentro de los que se destacan José M. Coellar, Felix Palavicini, José Ugarte, Arturo G. Múgica, Rodrigo Cárdenas, José Inés Novelo, Antonio Manero y Diego Arenas Guzmán. Dicha labor consistió en la identificación de Venustiano Carranza con los ideales de unificación latinoamericana propios del discurso bolivariano; en la movilización de los idearios independentistas de toda la región como parte de una historia común de resistencia contra los imperialismos decimonónicos y contemporáneos; en el perfilamiento de Venustiano Carranza y de la nación mexicana como potenciales conductores de un latinoamericanismo de cuño antiimperialista y, finalmente, en la identificación de la política internacional mexicana como ejemplo y ruta para las naciones latinoamericanas en aras de oponerse a las pretensiones panamericanistas planteadas por Estados Unidos a través de la Doctrina Monroe. Sobre la historia de El Pueblo y la prensa constitucionalista se consultaron: Jean-Pierre Bastian, "Los propagandistas del constitucionalismo en México (1910-1920)", en Revista Mexicana de Sociología, vol. 45, núm. 2, 1983, pp. 321-351; Celia del Palacio Montiel, "La prensa carrancista en Veracruz. 1915", en Folios, núm. 26, Universidad de Antioquía, pp. 3963; Francisco Iván Méndez Lara, "iVámonos para Veracruz! La prensa carrancista y su proyecto revolucionario: del puerto a la Ciudad de México (noviembre 1914-marzo 1915)", en Ulúa, núm. 24, Instituto de Investigaciones Histórico-Sociales de la Universidad Veracruzana, pp. 145-176; María del Carmen Ruíz Castañeda, "La prensa de la revolución, 1910-1917”, en Luis Reed y María del Carmen Ruíz Castañeda, El periodismo en México, 500 años de bistoria, México, Edamex, 1997; María Teresa Camarillo, "La prensa revolucionaria durante la etapa constitucionalista", en Laura Navarrete Maya y Blanca Aguilar Plata, La prensa en México 1810-1915, México, Addison, 1998; Javier Garciadiego, "La prensa durante la Revolución mexicana", en Javier Garciadiego, Autores, editoriales, instituciones y libros: estudios de historia intelectual, México, Colegio de México, 2015. 
como el primer paso en la consecución de la "unión latino-americana", unión que era catalogada en sus páginas como "uno de nuestros más altos y nobles ideales nacionales" ${ }^{27}$ En el mismo sentido, las alocuciones de Carranza en torno al mismo tema eran reseñadas en primera página. En dichas intervenciones la unión latinoamericana era colocada como un imperativo del orden patriótico que de cierta manera, aunque muy soterrada aún, perfilaba a México como su iniciador y dirigente. ${ }^{28}$ De allí que en varias de sus alocuciones rutinarias, inmediatamente después de referirse al "ideal de unir a las diversas razas que forman la familia mexicana en una sola, fuerte y libre" se hiciera mención a que la "única medida para salvar las naciones latino-americanas del peligro de la absorción o de conquista por otra raza cualquiera es la solidaridad y la formación de un solo bloque continental". ${ }^{29}$

$\mathrm{Al}$ analizar en su conjunto las intervenciones, tanto de Carranza como de quienes escribían a su favor a través de algunos diarios, se puede apreciar la claridad en los términos en que dicha unidad latinoamericana debía oponerse a las pretensiones de Estados Unidos en la región. Para los ideólogos del constitucionalismo, la única forma de evitar "el triunfo de la 'fuerza material', la idolatría moderna en cuyos altares oficia Roosevelt y su partido", era por medio de "el triunfo de la "fuerza moral" que se sustentaba en "la fuerza del derecho", es decir, en la soberanía nacional. ${ }^{30}$

Así, el discurso constitucionalista apelaba a la emergencia de una "fuerza moral" con la cual se identifica plenamente y que a su vez se oponía y resistía a los embates de una "fuerza material" representada por Estados Unidos. Dicho de esta manera, el discurso constitucionalista no tenía nada de innovador, si se tiene en cuenta que prácticamente sobre

27 "Cantemos como nuestras las glorias de la América Latina", en El Pueblo, México, 8 de junio, 1916, p. 2.

28 "Monroismo y Panamericanismo. Perfidia y mercantilismo", en El Pueblo, México, 21 de junio, 1916, p. 2.

29 "La América Latina debe formar un solo bloque continental", en El Pueblo, México, 10 de junio, 1916, p. 1.; "La América Latina está con México", en El Pueblo, México, 11 de junio, 1916, p. 2.

30 "Entre Wilson y Wilson, está Carranza", en El Pueblo, México, 2 de junio, 1916, p. 1. 
los mismos postulados se basaba la obra cumbre de José Enrique Rodó publicada en 1900, misma que configuraría toda una corriente ideológica en el continente, ampliamente divulgada y conocida con el nombre de arielismo. ${ }^{31}$ No obstante, los postulados de Rodó y los arielistas no habían encontrado hasta aquel momento un escenario políico real y fecundo en el cual desplegar la potencialidad de su discurso. La ocasión, advertida y aprovechada por los intelectuales constitucionalistas, la dio la Expedición punitiva. A partir de allí se sustentó todo un discurso nacionalista y latinoamericanista al que no tardarían en acercarse aquellos sectores que ansiaban tener un lugar en él, hasta en ese momento restringido aparato político de la nación. Uno de esos sectores era el estudiantil.

Fue en este contexto que se llevó a cabo la cuarta sesión del CLEDF, durante la cual se determinó, entre otras cosas de orden administrativo, que todos aquellos asuntos que en adelante estuviesen relacionados con la organización y celebración del IICNE, ${ }^{32}$ serían competencia de la mesa directiva del CLEDF, presidida por el citado Jorge Prieto Laurens. Lo importante de esta decisión, más allá de que el grupo capitalino se atribuyera para sí la vocería del movimiento estudiantil, es que dicho grupo estaba estrechamente ligado al gobierno - debe recordarse que Carranza era quien financiaba sus reuniones- y por lo tanto compartía sus propuestas ideológicas. Esto explica el por qué una de las primeras convocatorias al Congreso Nacional llegó a hacerse en los siguientes términos: "Que recuerden que en el Segundo Congreso Nacional de Estudiantes descansa el porvenir de hispano-américa, porque en él se definirá la actitud que asumirán los latinoamericanos, ante el coloso del Norte, ante la Gran Re-

31 "El término 'arielismo' ha sido empleado tanto para resumir el mensaje de Ariel [obra cumbre del uruguayo José Enrique Rodó], como para referirse a cierta orientación del espíritu de esos años: una actitud, denominada también idealista, de descontento frente a la unilateralidad cientificista y utilitaria de la civilización moderna, la reivindicación de la identidad latina de la cultura de las sociedades hispanoamericanas, frente a la América Anglosajona". Carlos Altamirano, "Elites culturales en el siglo XX latinoamericano", en Carlos Altamirano [ed.], Historia de los Intelectuales en América Latina, Buenos Aires, Kats editores, 2008, p. 10.

32 La idea de celebrar el Segundo Congreso Nacional de Estudiantes fue del estudiante Gabino A. Palma, estudiante de la Escuela Normal de Profesores. 
pública Sajona, que pregona la Democracia con el Imperialismo más bruto que registra la historia de la humanidad", convocatoria a través de la cual el mismo grupo se adjudicaba la "formación del Alma Nacional y la formación del sentimiento hispano-americano en general". 33

Así pues, la identificación entre los objetivos del gobierno y los objetivos de los estudiantes había quedado manifiesta: Carranza asistía gustoso a cuanta invitación le era extendida por la junta directiva del CLEDF, ${ }^{34}$ mientras se servía de ellos para que organizaran y fungieran de anfitriones o maestros de ceremonias en las diversas veladas, cenas y homenajes que a propósito de las fiestas de Independencia de varios países latinoamericanos financió para agasajar a sus respectivos representantes diplomáticos. ${ }^{35}$ Dicha identificación y apoyo mutuo terminaron por hacerse explicitas a través de los diarios de la época, que no dudaban en señalar que "La juventud, en unos meses de educación liberal, se va convenciendo de que el Constitucionalismo entraña la redención nacional [... ] La juventud sin alardes ni patrioterías está ahora en su pueblo [...] la juventud altiva, de pie, erguida y heroica está ya al lado de la patria, del progreso y de la verdad, frente a frente del extranjero, del retroceso y de la mentira" . ${ }^{36}$

Los diversos homenajes, cenas y veladas mencionadas anteriormente fueron las ocasiones preferidas para que estudiantes, representantes del gobierno y hasta el mismo Primer Jefe del ejército constitucionalista expusieran y fueran perfilando de mejor manera su discurso de unidad latinoamericana. En cada una de las intervenciones, México se mostraba

33 "A todos los estudiantes de la República isalud!", en El Pueblo, México, 21 de junio, 1916, p. 1.

34 "Fiesta en honor de un grupo de estudiantes de Puebla", en El Pueblo, México, 6 de junio, 1916, p. 4.

35 "En honor de los pueblos Latinoamericanos", en El Pueblo, México, 7 de julio, 1916, p. 2; "Invitación a la velada que se efectuará hoy en honor de Venezuela y Argentina", en El Pueblo, México, 12 de julio, 1916, p. 2; "Hoy se efectuará una recepción solemne en el consulado de Colombia", en El Pueblo, México, 20 de julio, 1916, p. 1.; "La velada en honor de las repúblicas del Perú y Bolivia”, en El Pueblo, México, 11 de agosto, 1916, p. 4.; "Simpáticas manifestaciones de la solidaridad latino-americana ", en $E l$ Pueblo, México, 25 de agosto, 1916, p. 2.

36 "Frente a frente", en El Pueblo, México, 7 de julio, 1916, p. 1. 
siempre "unido por indisolubles vínculos de raza, de tradición, de historia y de ideales [en este caso] a la República Argentina y a la demás repúblicas hermanas del continente", ${ }^{37}$ se apelaba a la identificación heroica con los próceres independentistas suramericanos, a los cuales se dedicaban odas y semblanzas, ${ }^{38}$ y ante todo se hacía énfasis en que "la obra de unificar la raza latina en América, [...] de crear la patria soñada por el insigne autor de Ariel" correspondía "a los hombres nuevos, a los jóvenes americanos, [a los] alumnos de las escuelas universitarias", ${ }^{39}$ los cuales aprovecharon la confianza en ellos depositada para sugerir iniciativas como la creación de un nuevo Ateneo de México ${ }^{40}$ o el establecimiento de "clases especiales de Geografía e Historia de América, con el fin de ir inculcando en la niñez ideas que la orienten hacía la unión latinoamericana". ${ }^{41}$

En este mismo sentido, el interés político por entablar mejores relaciones con las Repúblicas del sur del continente llevó al gobierno constitucionalista a preguntarse sobre la misión y eficiencia del cuerpo diplomático que allí lo representaba. En sus balances, la mayoría de ellos, iniciados desde el porfiriato, se resaltaba cómo la diplomacia mexicana había carecido desde siempre de una fuerte direccionalidad e independencia ${ }^{42}$ pero ante todo se resaltaba el hecho de que "ningún gobernante de México, antes de Carranza, había sabido mantenerse independiente de la tutela diplomática americana”, ${ }^{43}$ llegando incluso a señalar la existencia e

37 "Los discursos cambiados en la recepción del Sr. Ministro de la República Argentina", en El Universal, México, 9 de julio, 1916, p. 3.

38 "La independencia de Colombia", en El Pueblo, México, 20 de julio, 1916, p. 1.

39 "Alocución pronunciada por el lic. José Mariano Pontón, en la velada verificada en la Escuela Nacional preparatoria en honor de la República del Uruguay", en El Pueblo, México, 28 de agosto, 1916, p. 2.

40 "La cohesión del alma de la juventud literaria", en El Pueblo, México, 27 de agosto, 1916, p. 3 .

41 "Inculcar ideas para formar la unión Latinoaericana", en El Pueblo, México, 27 de agosto, 1916, p. 3.

42 "Cuál ha sido y cuál debe ser la misión de nuestros diplomáticos en el extranjero", en El Universal, México, 20 de octubre, 1916, p. 3.

43 "El Primer Jefe", en El Universal, México, 24 de octubre, 1916, p. 3. 
implementación de una "Doctrina Carranza' para la América [Latina]". ${ }^{4}$ Cabe resaltar que aunque por esta época ya se hiciera mención a algo llamado "Doctrina Carranza", no existía aún ningún documento oficial que recogiera el conjunto de principios que delinearon la política diplomática del constitucionalismo. Algo equiparable sólo aparecería el $1^{\circ}$ de septiembre de 1918 cuando el Presidente de la República en mensaje al Congreso de la Unión se manifestara al respecto. ${ }^{45}$

Lo que sí se hace evidente es que, a partir de la segunda mitad de aquel año de 1916, los intelectuales cercanos al gobierno se dieron a la tarea de abordar específicamente el tema de la posición ideológica del constitucionalismo para América Latina. ${ }^{46}$ En diarios como El Pueblo se inauguró una columna editorial llamada "sección Latino-Americana" donde se reflexionaba sobre las principales noticias del acontecer latinoamericano, ${ }^{47}$ pero ante todo atacaba duramente la política estadounidense conocida como Doctrina Monroe, ${ }^{48}$ lo propio se hizo desde las páginas del recién fundado diario constitucionalista El Universal, ${ }^{49}$ que en su sección titulada "Página Doctrinaria", se dio a la tarea de analizar y criticar meticu-

44 "Nuestros representantes en el extranjero", en El Universal, México, 3 de octubre, 1916, p. 3.

${ }^{45}$ Cabrera, op. cit., pp. 108-112.

46 El primer número de El Universal estaba encabezado por dos frases en los extremos superiores de la primera página. Una de Simón Bolívar que reza: "Yo no Soy Napoleón ni quiero serlo. Por nada del mundo imitaré a César, ni mucho menos a Iturbide. El título de Libertador sobrepuja a todos aquellos de que pudiera gloriarse el orgullo humano", y otra de Venustiano Carranza que dice: "Reinará sobre la tierra la verdadera justicia cuando cada ciudadano, en cualquier punto que pise del planeta, se encuentre dentro de su propia nacionalidad".

47 "Una faz del porvenir de la américa Latina", en El Pueblo, México, 28 de agosto, 1916, p. 2.

48 "Los dos panamericanismos", en El Pueblo, México, 29 de agosto, 1916, p. 3.

49 El fundador de El Universal, Felix Palavicini, de antaño maderista y fiel colaborador de Carranza, abandonó la Secretaría de Instrucción Pública en 1916 para dar inicio a este diario matutino, que tenía por propósito dar soporte periodístico e ideológico al constitucionalismo, una vez que fue convocado el Congreso Constituyente. El diario estuvo siempre ligado al gobierno constitucionalista y defendió los postulados emanados de la constitución de 1917 hasta 1923, fecha en la que se separa de la dirección del periódico. 
losamente la citada Doctrina, ${ }^{50}$ haciendo particular hincapié en que a ésta sólo podría enfrentársele otra de la misma índole, pero surgida desde la concordia de las naciones latinoamericanas y basada en una conjunción de patriotismo e internacionalismo que impidiese el dominio de una nación sobre las demás. ${ }^{51}$

Como era de esperarse, los dirigentes del CLEDF no fueron ajenos al creciente interés de los intelectuales constitucionalistas por América Latina. Así pues, por encargo del Primer Jefe y con la ayuda y patrocinio de El Universal, ${ }^{52}$ se apersonaron de la organización de las manifestaciones, veladas y homenajes que la capital de la República presenció a propósito de la Fiesta de la Raza, ${ }^{53}$ actividades que se caracterizaron especialmente por dejar atrás el discurso laudatorio sobre la herencia hispánica ${ }^{54}$ y centrarse de preferencia en el ensalzamiento de la unidad latinoamericana. ${ }^{55}$ No obstante, en esta ocasión la propuesta más contundente de parte de los dirigentes CLEDF, y que deja en evidencia la comunión entre el gobierno y los cuadros del movimiento estudiantil, fue la de "nombrar un representante en las repúblicas Centro y Sud-Americanas, con objeto de relacionar y estrechar los lazos de amistad entre los estudiantes de aquellos países y los de la República Mexicana". ${ }^{6}$ Tal propuesta fue recibida con simpatía por

50 "La verdadera Doctrina de Monroe", en El Universal, México, $1^{\circ}$ de octubre, 1916, p. 3; "La Doctrina de Monroe y la guerra actual", en El Universal, México, 5 de octubre, 1916, p. 3 .

51 "Patriotismo e internacionalismo", en El Universal, México, 2 de octubre, 1916, p. 3.

52 “'El Universal' patrocina la Fiesta de la Raza que se celebrara el día 12", en El Universal, México, 11 de octubre, 1916, p. 1.

53 "La Fiesta de la Raza se celebró ayer con inusitado entusiasmo", en El Universal, México, 13 de octubre, 1916, p. 1.

54 Reseña de las ceremonias efectuadas en México con motivo de la fiesta de la raza y organizadas por la universidad nacional, México, Editor no identificado, 1919. (clasificación LIBRUNAM: E120 M482)

55 "Una manifestación obrero-estudiantil para celebrar la Fiesta de la Raza", en $E l$ Universal, México, 11 de octubre, 1916, p. 1.

56 "El Congreso local Estudiantil nombró ya su representante en las Repúblicas SudAmericanas", en El Pueblo, México, 13 de agosto, 1916, p. 5.; "Una sesión del Congreso Local de Estudiantes del Distrito Federal", en El Pueblo, México, 14 de noviembre, 1916, p. 6. 
parte del gobierno, quien a través de El Universal resaltó la feliz coincidencia de los jóvenes con el proyecto constitucionalista de acercamiento con el resto de las naciones latinoamericanas. ${ }^{57}$

Así pues, se puede afirmar que, si bien el discurso latinoamericanista generado en México a lo largo de 1916 no presentaba diferencias sustanciales con discursos similares que desde la aparición de Ariel venían circulando en el resto del continente, sí se había generado en medio de una coyuntura política específica, como lo fue la Expedición punitiva. Esta coyuntura posibilitó la identificación inmediata de este discurso con un proyecto político concreto del constitucionalismo. Proyecto al que por sus características se adhirieron rápidamente los jóvenes intelectuales del CLEDF, quienes encontraron en la propuesta gubernamental, no sólo un apoyo, sino también cierta legitimidad para sus iniciativas gremiales, al tiempo que el régimen encontraba en ellos un soporte al interior de las clases medias y de paso unos excelentes representantes diplomáticos, que comunicarían a Latinoamérica los logros alcanzados por la Revolución mexicana.

\section{FORMAR UNA NACIÓN DE TODAS LAS HERMANAS}

Como se ha señalado, el papel desempeñado por los estudiantes en la iniciativa constitucionalista de acercamiento con las naciones del sur del continente se había limitado, en cierta medida, a seguir y reproducir el discurso latinoamericanista que hasta ahora venía siendo perfilado por los intelectuales cercanos al gobierno. Un discurso que, como ya se ha dicho, no se diferenciaba mucho del heredado del arielismo, pero que por lo pronto había servido de vaso comunicante entre las iniciativas gubernamentales y los cuadros estudiantiles.

No obstante, para principios de 1917, la conciencia de ser una parte fundamental de la iniciativa constitucionalista, surgida entre otras razones por el protagonismo que el mismo Carranza les había otorgado, llevó a

57 "La juventud es la esperanza de la Patria", en El Universal, México, 16 de diciembre, 1916, p. 1. 
que los estudiantes buscaran referentes ideológicos más cercanos a su experiencia, desde los cuales pudieran cimentar y legitimar su participación política. El primero de ellos en aparecer en escena fue el político y escritor argentino Manuel Ugarte.

De antaño conocido, especialmente por el conflicto que su presencia y sus posturas antiestadounidenses habían generado, no sólo entre los estudiantes y el gobierno de Madero, sino también entre este último y el gobierno de Estados Unidos, ${ }^{58}$ pero sobre todo por su férrea defensa internacional del proceso revolucionario mexicano y la denuncia de la intervención estadounidense en Veracruz, ${ }^{59}$ Manuel Ugarte era considerado por la joven intelectualidad de entonces como uno de los más importantes referentes y adalides de la unidad latinoamericana. Su discurso latinoamericanista carecía de los "perfiles netamente reaccionarios" que caracterizaban al "espiritualismo de Rodó". ${ }^{60}$ Si bien sus principales reflexiones también apuntaban al problema del antiimperialismo y de la unidad latinoamericana, Ugarte se alejaba tangencialmente del pensador uruguayo en que los abordaba desde una perspectiva claramente socialista. ${ }^{61}$

Desde este enfoque el escritor argentino afirmaba que, ante el carácter reaccionario que podía investir el nacionalismo en los países de aspiraciones capital-imperialistas, debía estructurarse y levantarse un nacionalismo progresista desde cada uno de los países colonizados o semi-colonizados de América Latina, que los uniese en un solo frente bajo el

58 Garciadiego, Rudos contra científicos..., p. 306.

59 Manuel Ugarte, Contra la intervención en México a la juventud y al pueblo (1914). Volante de la Asociación Latinoamericana invitando a un acto para el 22 de junio de 1914 cuyo orador de fondo es su presidente Manuel Ugarte. Redactado por el propio Ugarte. Archivo General de la Nación Argentina y Manuel Ugarte, El ejemplo de México (1914), en Manuel Ugarte, La nación latinoamericana, Caracas, Biblioteca Ayacucho, 1978, pp. 29-31.

60 Manuel Ugarte, La nación latinoamericana, Caracas, Biblioteca Ayacucho, 1978, p. 19.

${ }^{61}$ Miguel Ángel Barrios, El latinoamericanismo en el pensamiento político de Manuel Ugarte, Buenos Aires, Biblios, 2007; Julio Ramos, Latinoamericanismo a contrapelo, Colombia, Universidad del Cauca, 2015. 
estandarte de la liberación nacional, ${ }^{62}$ quedando así el discurso de Rodó, si bien no quebrantado, por lo menos sí superado en lo referente a la acción nacionalista concreta de tinte socialista.

Estas características del pensamiento de Ugarte fueron identificadas y medianamente apropiadas por los cuadros dirigentes del CLEDF, quienes encontraron en ellas la mejor forma de llenar de nuevos contenidos ideológicos el creciente interés del gobierno mexicano por abanderar un movimiento, por lo pronto diplomático, de unidad latinoamericana. No obstante, es preciso advertir, que si bien la lectura de Manuel Ugarte fue prolífica entre los jóvenes intelectuales del CLEDF, en ningún momento el Congreso tomó una direccionalidad ideológica abiertamente socialista.

Así pues, la oportunidad para hacer manifiesta su cercanía a los postulados de Ugarte fue la invitación que los dirigentes del CLEDF hicieron a algunas organizaciones americanistas, entre ellas de la Unión Latino-americana presidida por el mismo Manuel Ugarte, ${ }^{63}$ a participar en la condena conjunta por la intervención estadounidense en Santo Domingo, sobre la que ninguna queja se había producido hasta el momento en que, dicen los diarios, "los estudiantes de México, interpretando el sentir general del país y guiados por los más puros y más nobles sentimientos de raza, dirigieron a las Asociaciones Latino-Americanistas, enérgicos mensajes de protesta por el salvaje atentado yanqui, invitando así mismo, a todos sus hermanos de América a protestar por él". ${ }^{64}$

Dicha convocatoria redundó en un telegrama de adhesión de parte de Ugarte a la iniciativa estudiantil mexicana, fechado el 27 de enero de 1917, y el inicio de los preparativos, a partir del mes de marzo, de una serie de conferencias a los cuales fue invitado el pensador argentino por

${ }_{62}$ Manuel Ugarte, Mi campaña hispanoamericana, Barcelona, Editorial Cervantes, 1922.

63 La Unión (Asociación) Latino-americana, surgió en 1914 de la transformación del Comité Pro-México en esta nueva asociación pocos años después. El acta de fundación puede consultarse en Manuel Ugarte, La nación latinoamericana, Caracas, Biblioteca Ayacucho, 1978, p. 28.

64 "Protesta estudiantil por la intervención de Sto. Domingo", en El Universal, México, 22 de enero, 1917, p. 1.; "La intervención de E.U. en la República de Sto. Domingo", en El Universal, México, 29 de enero, 1917, p. 1. 
la Universidad de México. ${ }^{65}$ Fue así como para principios de abril de 1917 se reunió una comisión del CLEDF encargada de verificar los múltiples homenajes de los que sería objeto el político argentino, dentro de los que se contaban recepciones, conciertos, peleas de gallos, demostraciones deportivas y veladas teatrales, entre múltiples eventos públicos a los que estaban llamados estudiantes, obreros y el pueblo en general. ${ }^{60}$

Durante su estadía en México, Ugarte tuvo también la oportunidad de entrevistarse con Venustiano Carranza. En su encuentro, recreado tiempo después, le sorprendió gratamente la coincidencia que tuvieron en cuanto a su animadversión al imperialismo estadounidense y el señalamiento manifiesto de que su arribo a México había sido gestado desde la universidad, aun en contra de los deseos de Estados Unidos: "Es una invitación de la Universidad - contestó Carranza- y en México, como en los Estados Unidos, las universidades son autónomas. No puedo tomar ninguna medida para que el escritor que debe visitarnos no desembarque en nuestras costas [... $] "{ }^{67}$ Como se puede observar, Ugarte contaba, por un lado, con el visto bueno del gobierno para exponer abiertamente sus postulados e iniciativas políticas, y por el otro, con una comunidad universitaria que esperaba no sólo escuchar al intelectual argentino sino también interactuar con él y con sus ideas.

Por lo anterior, Ugarte no dudó un momento en arengar grandilocuentemente sobre su ya consabida prédica latinoamericanista que, justo por los días de su estadía en México, estuvo permeada por un problema

65 "Manuel Ugarte viene a México a hacer labor latinoamericana", en El Demócrata, México, 30 de marzo, 1917, p. 1. Si bien estas afirmaciones son hechas por Manuel Ugarte en la entrevista realizada por $E l$ Demócrata y consignadas además en el inicio de la conferencia que impartió el 11 de mayo en el teatro Ideal de México, Pablo Yankelevich afirma y sustenta en documentos de la Embajada de México en Argentina que dicha invitación se hizo en octubre de 1916 a través de un documento oficial entregado por Isidro Fabela al mismo Ugarte. Pablo Yankelevich, "Una mirada argentina de la Revolución mexicana. La gesta de Manuel Ugarte (1910-1917)", en Historia Mexicana, México, vol. 44, núm. 4, abril-junio de 1995, p. 664.

66 "Manuel Ugarte llegará hoy a México", en El Demócrata, México, 11 de abril, 1917, p. 1.

67 Manuel Ugarte, La nación latinoamericana, Caracas, Biblioteca Ayacucho, 1978, p. 316. 
de trascendencia mundial como lo fue la decisión de varios países latinoamericanos de apoyar a Estados Unidos en su declaración de guerra a Alemania, posición que Ugarte condenó públicamente durante sus intervenciones, llegando al extremo de reconocer sus inclinaciones por el bando germano, lo que no pocas veces causó resquemores entre sectores de la sociedad más favorables al bando de los aliados. ${ }^{68}$ Con la partida de Ugarte, lejos de quedar zanjado, este debate siguió vigente en el ambiente intelectual y político del México de la época, generando, como se verá más adelante, desencuentros entre sus participantes, dentro de los cuales se hallaban los dirigentes del movimiento estudiantil.

Por otra parte, la visita de Ugarte había surtido el efecto de generar inquietud entre los universitarios de la capital, quienes como se dijo anteriormente, componían el grueso del público que acompañó e interpeló al intelectual argentino durante su estadía en el país. Los resultados de dicha inquietud se vieron reflejados en la continuación de las sesiones extraordinarias con vista a celebrar el IICNE, para lo cual se citó a una asamblea extraordinaria a la que fueron invitados Venustiano Carranza y varios miembros del cuerpo diplomático de los países latinoamericanos con representación en México. La razón de esta particular convocatoria no tenía nada de inocente, por el contrario, obedeció a que en la señalada sesión, celebrada el 29 de julio de 1917, se dio lectura a una proposición del CLEDF, en la cual se instaba al gobierno nacional y a la Secretaría de Relaciones Exteriores para iniciar un intercambio estudiantil con Suramérica, en respuesta a las invitaciones que "por conducto del escritor argentino, Don Manuel Ugarte" le habían extendido varias "Asociaciones científicas de las distintas provincias de aquellas Repúblicas". ${ }^{69}$

El texto, firmado por Miguel Torner y Juan Espejel, a la sazón recientemente nombrados presidente y vicepresidente del CLEDF, pedía "al Señor Presidente Carranza, que por conducto de la Secretaría de Estado, Departamento del Exterior, se lleve a cabo un intercambio cultural con las

68 Yankelevich, op. cit., p. 669.

69 "Tuvo gran convocatoria la sesión del Congreso Nacional de Estudiantes", en Excélsior, México, 30 de julio 1917, p. 7. 
repúblicas sudamericanas por medio de comisiones de estudiantes", mismas comisiones que en la petición se perfilaron como adalides del ideal latinoamericanista, en la medida en que se llegó a señalar que a través de ellas "los mexicanos se sentirán capaces de todos los esfuerzos por conquistar su mejor porvenir y podrán contestar a España, cuando pregunte a las naciones de este continente: '¿cuál es vuestro ideal?' México responderá: 'formar una nación de todas las hermanas"' ${ }^{70}$ En este sentido, pocos días después de la velada mencionada, El Universal publicaría:

Aceptada por el C. Presidente de la República la idea de establecer un intercambio entre los estudiantes mexicanos y las demás naciones latinoamericanas, $[\ldots]$ el Congreso Local Estudiantil convocó a los estudiantes de todas las escuelas profesionales de la capital, para verificar una selección de los elementos que como Agregados o Secretarios de las Legaciones mexicanas en los citados países, vayan a desempeñar la labor de la que hacemos referencia. ${ }^{71}$

En dicha sesión, llevada a cabo el 19 de agosto de 1917, fueron designados como representantes para Argentina, Salvador Ordoñez y Eduardo Beltrán; para Uruguay, Manuel Gómez Morín y Vicente Lombardo Toledano; para Brasil, Enrique Soto Peimbert y Carlos Pellicer Cámara, y para Chile, Gabino Palma y Feliciano Escudero Cruz. ${ }^{72}$

Pese al entusiasmo con el que fue desarrollado el acto de elección y designación de los representantes, ninguno de ellos viajó a su destino respectivo. Solamente Enrique Soto Peimbert y Adolfo Desentis, después de una nueva y apresurada elección, fueron elegidos por el CLEDF como sus representantes ante el Congreso Internacional Latino-Americano que se llevó cabo el tercer domingo del mes de octubre de $1917 .{ }^{73}$

70 "Los estudiantes de la C. de México organizaron una simpática fiesta de confraternidad indolatina", en El Demócrata, México, 30 de julio, 1917, p. 8.

71 "Estudiantes que irán a las legaciones", en El Universal, México, 20 de agosto, 1917, p. 3.

72 "Los estudiantes que harán diplomacia y confraternidad", en La Lucha, periódico de estudiantes, México, 30 de septiembre 1917, p. 1.

73 "Viaje de los dos delegados a un congreso", en El Universal, México, 15 de septiembre, 1917, p. 2. 
Es necesario señalar que para la época de la elección de representantes estudiantiles, el CLEDF en su conjunto, pero en especial sus dirigentes, distaba mucho de ser un grupo homogéneo. Por un lado se encontraban los denominados "políticos", que en cierta medida eran concebidos como el grupo fundador del Congreso, quienes bajo la batuta de Jorge Prieto Laurens - como se señaló en su momento, primer presidente del CLEDF- habían jalonado la organización estudiantil, reconociendo como antecedente el Primer Congreso Nacional de Estudiantes celebrado en la Ciudad de México en 1910. A este grupo también pertenecían Enrique Soto Peimbert, Miguel Torner -presidente en ejercicio durante las designaciones de delegados-, Juan Espejel -vicepresidente- y Feliciano Escudero Cruz, entre otros. Mientras que a su lado cobraba fuerza rápidamente y reclamaba un lugar en la dirigencia estudiantil el grupo conocido bajo el nombre de los "siete sabios", ${ }^{74}$ liderado por Manuel Gómez Morín y Vicente Lombardo Toledano. ${ }^{75}$

La confrontación principal entre los dos grupos radicaba en el tipo de enfoque y relación que el CLEDF debía mantener con el gobierno. Para "los sabios" dicha relación tenía que plegarse más a lo cultural que a lo estrictamente político, mientras que para "los políticos" era una prioridad que el movimiento estudiantil se permitiera hacer política abiertamente del lado del gobierno. ${ }^{76}$

Dichas rencillas fueron medianamente disimuladas desde la llegada del constitucionalismo al poder y de su desarrollo se hablará más adelante, pues redundaron en la reorganización del movimiento estudiantil a finales de 1917. Sin embargo, como se dejó planteado párrafos atrás, el debate de los intelectuales sobre la neutralidad de México en la Primera

74 Con respecto del grupo de "Los siete sabios" sobresalen los estudios de Genaro Salinas Quiroga, Los siete sabios de México, México, Universidad Autónoma de Nuevo León, 1980; Enrique Krauze, Caudillos culturales en la Revolución mexicana, México, Siglo XXI, 1982. Al prestigioso grupo de intelectuales pertenecían Manuel Gómez Morín, Vicente Lombardo Toledano, Teófilo Olea y Leiva, Alberto Vásquez del Mercado, Jesús Moreno Vaca, Antonio Castro Leal y Alfonso Caso.

75 Lourdes Velázquez Albo, Los Congresos nacionales universitarios y los gobiernos de la Revolución 1910-1933, México, IISUE-UnAm/Plaza y Valdés, 2007, p. 36.

76 Krauze, op. cit., pp. 99. 
Guerra Mundial, ${ }^{77}$ azuzado desde la vista de Manuel Ugarte, aún estaba vigente y los jóvenes intelectuales mexicanos no pudieron y no quisieron eludir la oportunidad de hacer parte de él, puesto que ya para entonces tenían una concepción bien formada sobre la importancia de su organización en el debate político de los asuntos nacionales.

Al respecto, el primer desencuentro se dio en una reunión de la mesa directiva del CLEDF, citada por su presidente Miguel Torner, que tenía como objetivo el de llegar a una posición conjunta de la organización estudiantil en torno "de la actitud que debían tomar ante el problema de la política internacional", ${ }^{7}$ tema sobre el que después de escuchar proposiciones encontradas y presenciar recriminaciones mutuas entre los convocados, se dio por zanjada la discusión sin llegar a un acuerdo conjunto, dándose por suspendida la sesión.

Este hecho suscitó entre la comunidad estudiantil una gran inquietud, que derivó en que para los primeros días de noviembre se convocara a una asamblea general para discutir con el grueso del estudiantado capitalino la posición que debía asumir el Congreso ante los problemas de política internacional del gobierno.

En la sesión, generosamente cubierta por los diarios El Demócrata y Excélsior, "hubo de todo: gritos, silbidos, protestas enérgicas y no siempre mesuradas, graves injurias entre los oradores y antes de comenzar la junta golpes y disputas". ${ }^{79}$ El primero en recibir recriminaciones por parte del grupo de "los sabios" fue Jorge Prieto Laurens, quien fue tildado de "germanófilo por formar parte de la camarilla que seguía a Manuel Ugarte", a lo que éste respondió acusando a Gómez Morín y a Lombardo Toledano de "furibundos aliadófilos que a pesar de ello habían carecido de valor civil

77 Roberta Lajous, "La Revolución mexicana y la Primera Guerra Mundial, 1911-1920", en Roberta Lajous, Historia mínima de las relaciones exteriores de México, 18212000, México, Colegio de México, 2012, pp. 145-176.

78 "Discute la actitud del grupo estudiantil ante la actual situación internacional", en $E l$ Universal, México, 22 de octubre, 1917, p. 2.

79 "Los estudiantes están por conservar la neutralidad", en Excélsior, México, 11 de noviembre, 1917, p. 1. 
para manifestarlo así". ${ }^{80}$ Por espacio de una hora, señalan los diarios, las arengas y contraargumentos iban y venían en medio de una algarabía del público asistente que aumentaba en energía e improperios con cada discurso. ${ }^{81}$ No obstante, el intercambio de acusaciones de simpatías soterradas, ya fuera hacía el bando de la entente ${ }^{82} \mathrm{o}$ al de los aliados, no pasó de ser la puesta en escena del pulso político de los dos grupos en contienda por el liderazgo del CLEDF. Así lo evidencia la aprobación, conjunta y sin reparos de ningún tipo, de una resolución en la que se le renovaba la confianza al gobierno nacional "de que éste siempre se preocupará por obrar conforme lo exijan los más altos intereses nacionales" dejando por sentado que por esta razón el "Congreso Local Estudiantil del Distrito Federal, se abstendrá de participar en toda labor de propaganda directa o indirecta en favor o en contra de cualquiera de las actitudes que se proponen para la República ante este grave problema". 83

Pese a la aparente concordia con la que terminó el asunto de la neutralidad, el grupo de "los sabios" había logrado que, luego de la renuncia de Miguel Torner a la presidencia del CLEDF y de que su puesto fuera asumido por el vicepresidente Juan Espejel, se nombrara como Secretario para el exterior a uno de sus más jóvenes integrantes, el estudiante de la Escuela de Jurisprudencia Miguel Palacios Macedo, quien en adelante sería el encargado de tratar los asuntos de representatividad estudiantil en el extranjero directamente con el gobierno.

Palacios Macedo empezó a desarrollar tal función con un notable, aunque exagerado entusiasmo, puesto que para finales de noviembre de 1917, seleccionó a doce nuevos alumnos de diferentes escuelas, que se sumarían a los ocho ya electos para representar a los estudiantes mexicanos

80 "La neutralidad es sotenida por la clase estudiantil", en El Demócrata, México, 8 de noviembre, 1917, p. 1.

81 "Ratifica el Congreso Local Estudiantil, sus acuerdos sobre la neutralidad que debe conservar la República", en El Demócrata, México, 2 de noviembre, 1917, p. 1.

82 Jean Meyer, "ifue México germanófilo de 1914 a 1918?", en Jean Meyer, De una revolución a la otra: México en la bistoria. Antología de textos, México, Colegio de México, 2013, pp. 161-180.

83 "Tormentosa junta tuvieron los estudiantes", en Excélsior, México, 2 de noviembre, 1917, p. 1. 
en Latinoamérica. ${ }^{84}$ Sin embargo, la importancia de la gestión de Palacios Macedo radica en que sentó las bases para que, si bien los estudiantes seleccionados viajarían a sus respectivos países como miembros de las legaciones mexicanas, estos irían en calidad de estudiantes a continuar los estudios que adelantaban en las diferentes escuelas de la Ciudad de México, y así fue como efectivamente sucedió. ${ }^{85}$

La elección de Palacios Macedo en el cargo de Secretario para el exterior representó para el grupo de "los sabios" un importante paso para consolidar su influencia dentro del CLEDF. Dicha influencia también se puede advertir en la propuesta y aprobación de convertir al CLEDF en una organización federativa que agrupara a los distintos Congresos estudiantiles que para aquel entonces existían en el país. ${ }^{86}$ La Federación, como lo señala Carlos Pellicer en una conferencia dictada en Bogotá, cuando estuvo allí como su representante, se proponía como una organización independiente del poder gubernamental, lo cual había sido una de las banderas más defendidas por el grupo de "los sabios" ${ }^{87}$ Pero lo que sin duda representó su primacía política al interior de la organización estudiantil mexicana fue el hecho de que el primer presidente de la mencionada Federación Nacional de Estudiantes fuera el propio Miguel Palacio Macedo.

84 "Estudiantes pensionados a Sud-América", en Excélsior, México, 24 de noviembre, 1917, p. 1. Los nuevos nombres integrados a la iniciativa fueron: Rafael Ferriz, a Ecuador; Ernesto Ortega, a Perú; Fidencio Hernández, a Bolivia; Miguel A. Guerrero a Colombia, Luis Norma a Paraguay y Manuel Mazari a Venezuela. Adicionalmente José Valenzuela, David Gutiérrez, Miguel Heredia, José Farell, José Breceda y Ladislao Montero fueron postulados para hacer lo propio en varios países Centroamericanos.

85 "Estudiantes mexicanos en países de Sudamerica", en El Demócrata, México, 24 de noviembre, 1917 , p. 4.

86 "La sesión de Clausura del C. Local Estudiantil", en Excélsior, México, 5 de diciembre, 1917, p. 1.; "Trascendentales reformas al Congreso estudiantil", en Excélsior, México, 26 de noviembre, 1917, p. 7.; "Organizaciones estudiantiles", en Boletín de la Universidad, México, t. I, núm. 1, diciembre de 1917, pp. 244-248.

87 Conferencia dictada por Carlos Pellicer Cámara en la Sala Samper de la Biblioteca Nacional de Colombia ante los estudaintes [sic] bogotanos (manuscrito), Bogotá, 25 de julio, 1919, Fondo Reservado de la Biblioteca Nacional de México (en adelante FRBNM), México, Archivo Carlos Pellicer (en adelante ACP), sec. 32, caja 234, carp. 38, f. 3-29, p. 28. 
Ahora bien, pese a la entusiasta labor de Palacios Macedo como Secretario del exterior, las urgencias económicas del gobierno constitucionalista y la perspicacia que suscitó el cambio de direccionalidad del gremio estudiantil hicieron que, para mediados de diciembre de 1917, ya una vez terminadas las clases y las sesiones ordinarias del Congreso estudiantil, se publicara la noticia de que los seleccionados por la Secretaría de Relaciones Exteriores, al mando del señor Ernesto Garza Pérez, habían sido nada más nueve estudiantes, "los señores E. M. del Campo, Santiago Serrano, Victoriano Lerandt, Manuel Mazari, Carlos Pellicer, E. Hernández, Gabino Palma, M.A. Guerrero y Luis Norma", que se dirigirían a "Argentina, Brasil, Chile, Uruguay, Ecuador, Perú, Bolivia, Colombia y Venezuela" ${ }^{88}$ respectivamente.

El año de 1917 concluiría así con una organización estudiantil consolidada y altamente propositiva en lo político. Muestra de ello fue el papel activo que el CLEDF desempeñó como interlocutor principal del mensaje latinoamericanista de Manuel Ugarte, el cual serviría de sustrato, no sólo para robustecer su iniciativa de enviar representantes estudiantiles a los países suramericanos, sino también para tomar conciencia de que su madurez política los dotaba de cierta legitimidad para opinar y ser tenidos en cuenta, como grupo, en delicados asuntos de Estado como lo fue la neutralidad de México durante la Primera Guerra Mundial. Por otra parte, el robustecimiento político de la organización también se hizo manifiesto en el surgimiento de debates y pugnas ideológicas, entre grupos de intelectuales bien definidos, al interior de la organización estudiantil, que se planteaban básicamente el tipo de relación que debían mantener con el gobierno constitucionalista. Un tema que, como se verá más adelante, no hizo más que profundizarse durante el año de 1918.

88 "Estudiantes que por disposición del gobierno van a concluir sus estudios a diversos paises de Sud-América", en Excélsior, México, 10 de diciembre, 1917, p. 1. 


\section{UNIVERSIDAD Y POLÍTICA}

Para principios de 1918, entre los múltiples asuntos delegados por el gobierno para que los estudiantes sirviesen de apoyo o, aún más, de gestores en su política de acercamiento con las demás naciones latinoamericanas; entre los acalorados debates sobre la neutralidad o no de México en la guerra europea y entre la puja política por la dirigencia del CLEDF y su posterior transformación federativa, los cuadros del movimiento estudiantil poco tiempo habían dedicado en preocuparse seriamente por el motivo primigenio para el cual se había conformado el CLEDF, el cual, recapitulando, era la organización y celebración del IICNE. Dicha situación trató de ser atendida por los estudiantes pertenecientes al Congreso estudiantil de Mérida, quienes gestionaron la posibilidad de que el gobierno de Yucatán asumiera los gastos que originase la estadía de los delegados de los diferentes Congresos que existían en la República. ${ }^{89}$

Como era de esperarse, la elección de los delegados del CLEDF también fue objeto de disputa entre los "sabios" y los "políticos". Sin embargo, para evitar desgastes mayores y nuevas confrontaciones, la decisión se basó en un criterio francamente salomónico, ya que fueron designados dos de los miembros más importantes de cada grupo: Vicente Lombardo Toledano y Miguel Palacio Macedo, por "los sabios" y Jorge Prieto Laurens y Miguel Torner por "los políticos".

En dicha comisión también fueron incluidos por la Escuela Normal el estudiante Gabino A. Palma y por la Escuela Nacional Preparatoria el joven Carlos Pellicer Cámara, ${ }^{90}$ quien venía siendo el representante más importante de los preparatorianos al interior del CLEDF, a tal punto que fue el único estudiante cuya representación en Latinoamérica nunca fue puesta en duda o reemplazada bajo ningún criterio, en parte porque no se adscribió abiertamente a ninguno de los dos grupos en contienda aunque su inclina-

89 Para la fecha existían 13 Congresos Estudiantiles en todo el país: Chihuahua, Coahuila, Durango, Hidalgo, Jalisco, Ciudad de México, Michoacán, Nuevo León, Zacatecas, San Luís Potosí, Guanajuato, Puebla y Yucatán.

90 "En Mérida será el $2^{\circ}$ Congreso de estudiantes", en Excélsior, México, $1^{\circ}$ de enero, 1918, p. 1. 
ción siempre estuvo por hacer del movimiento estudiantil una plataforma desde la cual la juventud pudiese tener participación e influencia en los asuntos políticos de su nación, lo que no pocas veces le suscitó roces con los cuadros de la organización estudiantil cercanos al grupo de "los sabios".

Precisamente el tema de la participación o no de la organización estudiantil en asuntos estrictamente políticos fue uno de los asuntos que más causaron discusiones al interior del CLEDF, una vez que hubo fracasado el intento de celebrar el IICNE. ${ }^{91}$ Los debates nuevamente enfrentaron a los dos grupos en contienda, sólo que esta vez el asunto de las representaciones estudiantiles en el exterior también hizo parte del orden del día.

Las discusiones fueron abiertas por la lectura del artículo primero del plan de trabajo que presentó la Junta Directiva del CLEDF, mayoritariamente adepta a "los sabios". El artículo en mención rezaba así: "El Congreso acuerda abstenerse en lo absoluto de conocer e intervenir en asuntos que directa o indirectamente demanden o impliquen su participación en [... $]$ las vicisitudes de la política militante exterior o interior", declaración que implicaba el desconocimiento, por parte de la nueva dirigencia estudiantil, de acuerdos que en ese aspecto hubiese firmado la anterior, es decir, aquella liderada por el grupo de "los políticos", lo cual se hizo en estos términos; "Al mismo tiempo [el Congreso] declara insubsistentes todos los acuerdos emanados de los Congresos anteriores que en forma indiferente para el caso se encuentren en pugna con el criterio arriba expresado." ${ }^{22}$

Este ataque directo contra lo logrado por la labor de "los políticos", que representaba una franca crítica a su cercanía con el gobierno constitucionalista, fue enérgicamente contestado por Jorge Prieto Laurens, quien en su intervención señalaba la importancia de que la juventud or-

91 Es preciso señalar que la literatura consultada y los documentos a los que se tuvo acceso para esta investigación no dan cuenta satisfactoriamente del por qué no se pudo llevar a cabo el IICNE. Adelantar una reconstrucción minuciosa al respecto representaría una extensión infecunda para los objetivos de este capítulo, por lo cual, al igual que en otros trabajos, sólo se dejara constancia del hecho.

92 "Animados debates en el Congreso estudiantil", en Excélsior, México, $1^{\circ}$ de julio, 1918, p. 1. 
ganizada interviniera directa y propositivamente en los destinos políticos de la República, señalando además que el gobierno constitucionalista le había otorgado todas las garantías al movimiento estudiantil para que ello sucediera y muestra de ello había sido la acogida por parte del gobierno de la propuesta de enviar estudiantes como representantes diplomáticos a Suramérica. Sobre este hecho preguntó abiertamente: “icómo va a desarrollar el Congreso su acción en el exterior si no es por medio de la política?", cuestionamiento que fue respondido vagamente por Vicente Lombardo Toledano, quien propuso la necesidad de "educar a las masas populares, haciéndolas conocer sus deberes y derechos en la vida civil", 93 sin que al final de su intervención hubiera propuesto estrategias y actividades concretas al respecto. Finalmente, el artículo en mención no llegó a ser aprobado, aunque como medida de concordia el Congreso no se opuso a la participación individual de cualquiera de sus miembros en asuntos políticos, siempre y cuando estos lo hicieran a título personal y no gremial.

Sin embargo, lejos de quedar finiquitado, el debate en torno a la participación política del estudiantado siguió circulando entre la comunidad estudiantil suscitando múltiples reflexiones y posiciones al respecto. Una de ellas, quizá la más importante, pues redundó en todo un proyecto editorial, fue la de la revista estudiantil San Ev Ank, fundada a principio de julio de 1918 por iniciativa de un grupo de estudiantes liderado por el joven Luis Enrique Erro. ${ }^{94}$

La importancia de San Ev Ank radica en que a diferencia de sus predecesoras, como fue el caso de Gladios, fundada por el mismo Erro, se perfiló desde el principio como una publicación dedicada a tratar asuntos estudiantiles por encima de los artísticos o literarios, como sí lo hizo la ya nombrada Gladios durante su breve existencia. En San Ev Ank se encuentra, pues, la intención manifiesta de delinear políticamente los derroteros del movimiento estudiantil capitalino, tratando de establecer una posición

93 "Por el Congreso estudiantil. Acotaciones de un oyente", en San Ev Ank, t. I, núm. 1, México, 11 de julio, 1918, p. 22.

94 Para una semblanza de Enrique Erro, véase "Semblanza de Luis Enrique Erro Soler", en El cronista politécnico, año 8, núm. 32, México, enero-marzo 2007, pp. 2-5. 
neutra entre las dos perspectivas que venían haciendo carrera y contienda en cabeza de "los sabios" y "los políticos". De tal suerte que en sus páginas, si bien se alentó la participación política activa del estudiantado, ésta se planteó la posibilidad de hacerlo fuera de los canales convencionales facilitados por el constitucionalismo, lo que no precisamente significaba estar en contra de él.

En la revista hay todo un esfuerzo discursivo por resignificar conceptos como juventud y estudiante, pero también toda una apuesta por ubicar y señalar el papel que dichas categorías habrían de desempeñar en su momento histórico. Parten, pues, de la conciencia de ser los últimos eslabones en una cadena de guerras y revoluciones ${ }^{95}$ que demanda de ellos el perfilamiento de una nueva doctrina social y filosófica para México, más que una acción política tradicional, ${ }^{96}$ lo que hace que la propuesta se incline hacia la construcción moral del estudiante como sujeto político ${ }^{97}$ y a la denuncia de la "politiquería de baja estofa"98 a la que habían sido cooptados, se lamenta la revista, muchos estudiantes de la capital. Razón por la cual, desde San Ev Ank, se hace un llamamiento a la "constitución de una 'clase' estudiantil verdaderamente tal" que logre hacer, se planteaban con exceso de entusiasmo, de "la Universidad de hoy, la cuna del primer verdadero partido político de México". 99 El planteamiento indefectiblemente lleva a que en este proceso de concientización política se le otorgue un papel protagónico a la juventud intelectual mexicana, ${ }^{100}$ pero no para que diserten sus ideas en estrechos círculos literarios sino

95 "La juventud sin fe: el santuario de los dioses", en San Ev Ank, t. I, núm. 1, México, 11 de julio, 1918, p. 1.

96 "La Universidad Nacional", en San Ev Ank, t. I, núm. 1, México, 11 de julio, 1918, p. 13.

97 "La cuestión moral de la democracia", en San Ev Ank, t. I, núm. 2, México, 18 de julio, 1918, p. 1.

98 "El concepto del estudiante moderno", en San Ev Ank, t. I, núm. 2, México, 18 de julio, 1918, p. 14. en

99 "Los estudiantes y la política", en San Ev Ank, t. I, núm. 3, México, 25 de julio, 1918, p. 16. en

100 "Nuestra labor", en San Ev Ank, t. I, núm. 5, México, 8 de agosto, 1918, p. 1. 
para que "por el conducto de esta minoría llegue la obra educativa a todas las capas sociales". ${ }^{101}$

Considerando lo anterior, es que se puede comprender la importancia que tuvo para el estudiantado la organización y celebración por sus propios medios de una kermesse a inicios de septiembre con el fin de recolectar fondos para la organización estudiantil capitalina. ${ }^{102}$ Recuérdese que hasta este momento todas las actividades realizadas a nombre del CLEDF habían sido completamente financiadas por el gobierno constitucionalista, lo que representaba una ventaja, en parte, pero también dejaba manifiesta cierta subordinación a las directrices gubernamentales y por lo tanto una total falta de autonomía estudiantil. De tal suerte que el hecho de plantearse y llevar a cabo una celebración estudiantil con fondos propios de los estudiantes e independiente del financiamiento gubernamental (pero en donde fueron invitados el Presidente, los ministros del gabinete y el cuerpo diplomático acreditado), significaba el primer paso para establecer distancia con respecto de los usos tradicionales de la política y del mismo modo un grado, así fuese mínimo, de independencia respecto del gobierno.

Todo este revuelo en torno a la nueva concepción de la acción política del estudiantado que recorrió las páginas de San Ev Ank y el deslindamiento económico que representó la celebración de la kermesse, trajo consigo consecuencias lógicas que afectaron el proyecto de enviar representantes estudiantiles a diferentes países suramericanos, a tal punto que, para mediados de septiembre, durante la sesión ordinaria del CLEDF, se determinó que no se tendría en cuenta las designaciones de delegados hechas con anterioridad y que por lo tanto debería hacerse una nueva elección. ${ }^{103}$

101 "Asociaciones estudiantiles", en San Ev Ank, t. I, núm. 5, México, 8 de agosto, 1918, p. 6.

102 "Los estudiantes están preparando una gran kermesse", en El Universal, México, 3 de septiembre, 1918, p. 1.

103 "El Congreso estudiantil honrará la memoria de don Justo Sierra", en El Universal, México, 3 de septiembre, 1918, p. 1. 
Esta determinación fue el resultado, por un lado, de la limitación de las vacantes ofrecidas por el gobierno para los estudiantes, las cuales fueron reducidas a cinco (Argentina, Brasil, Chile, Colombia y Uruguay), y por el otro, de la implementación de un nuevo criterio para la elección, el cual hacía énfasis en que los estudiantes escogidos debían tener en claro que su misión "no es, como se dijera en un principio, servir en calidad de agregados a las legaciones que nuestro gobierno tiene en Sud-América, ni desempeñar una misión diplomática", todo lo contrario, en su calidad de pensionados los estudiantes elegidos no tendrían "más obligaciones que estudiar y hacer labor de acercamiento entre México y las Repúblicas Latino-americanas", labor que no obstante debía desarrollarse conforme a los lineamientos gubernamentales pues se hizo manifiesto que de la elección debían "eliminarse a aquellos que por sus antecedentes pudieran hacer labor contraria a los intereses del gobierno". ${ }^{104}$

Este doble condicionamiento dejaba de lado la posibilidad de ser elegidos, no sólo a los estudiantes más adeptos al constitucionalismo, sino también a aquellos que querían una mayor independencia con respecto al mismo. Así que resultaron elegidos los estudiantes Esteban Manzanera del Campo, Carlos Pellicer Cámara, Luis Norma, Pablo Campos Ortiz ${ }^{105}$ y Luis Padilla Nervo, todos jóvenes políticamente moderados, sin relación manifiesta con los grupos enfrentados al interior del Congreso y sin ningún vínculo personal con el gobierno, a excepción de Luis Padilla Nervo, quien era sobrino de Amado Nervo, embajador en Argentina y tutelado favorito del General Cándido Aguilar, por aquel entonces secretario de Relaciones Exteriores.

Como una muestra de confianza, el general Aguilar dejó en manos de Palacios Macedo y de los estudiantes escogidos la elección del país al cual irían a desarrollar su labor de acercamiento estudiantil, quedando

104 "Fueron elegidos los estudiantes que van a Sudamerica", en El Universal, México, 12 de septiembre, 1918, p. 1.

105 Es de resaltar que Campos Ortiz fue uno de los más prolíficos colaboradores de San Ev Ank en lo referente a la direccionalidad política que debía tener el CLEDF, del que fuera Secretario General hasta poco antes de su partida a Brasil 
asignado Luis Padilla Nervo a la Argentina, ${ }^{106}$ Pablo Campos Ortiz a Brasil, Luis Norma a Chile, Esteban Manzanera del Campo a Uruguay y Carlos Pellicer Cámara a Colombia.

De esta manera es que fue conformada la primera comisión de estudiantes mexicanos que visitaron Suramérica en representación de su gobierno. El 28 de septiembre el presidente de la República ofreció en el Castillo de Chapultepec una comida en honor a las misiones diplomáticas nombradas para Suramérica, en la cual pronunció un sentido discurso en donde sintetizó las intenciones del gobierno: "Llevad a las Naciones hermanas las más puras intenciones de unión espiritual e intelectual. La política de mi gobierno ha tendido y tenderá a esa unión tan ansiada que constituirá el bienestar supremo de la América Española."107

En los meses siguientes saldrían a sus respectivos países los jóvenes elegidos para representar al gobierno mexicano. El recuento de las actividades que allí se realizaron aún está por hacerse y sólo una investigación de más largo alcance podrá dar cuenta de ello.

\section{CONCLUSIONES}

A lo largo de este artículo se pudo comprender cómo los cuadros del movimiento estudiantil mexicano establecieron alianzas con el gobierno constitucionalista, a fin de fortalecer su organización gremial a nivel nacional, y cómo el gobierno de Venustiano Carranza aprovechó esas alianzas para hacerse de la simpatía de un importante sector de la clase media capitalina.

${ }^{106}$ Se sabe que la cercanía familiar con Nervo y la amistad con Cándido Aguilar fueron usadas por Luis Padilla para que le fuera asignado como país de destino Argentina, a despecho de Carlos Pellicer, quien había manifestado en primera instancia sus deseos de viajar al país austral. Véase Carta de Miguel Palacios Macedo a Carlos Pellicer Cámara, México, 17 de octubre, 1919, en FRBNM, México, ACP, sec. 35, caja 270, carp. 5, f. 14.

${ }^{107}$ Conferencia dictada por Carlos Pellicer Cámara en la Sala Samper de la Biblioteca Nacional de Colombia... op. cit., p. 28. 
La coincidencia de intereses entre el gobierno y los estudiantes facilitó que estos últimos formaran parte de las diversas iniciativas que Venustiano Carranza propuso, con el objetivo de buscar el apoyo y respaldo de las naciones latinoamericanas, en un momento en que las relaciones con Estados Unidos se habían deteriorado a causa de varios años de desencuentros políticos y económicos, que vinieron a tener su máximo momento de tensión, a propósito de los hechos desencadenados por el ataque de las fuerzas villistas a Columbus.

Así pues, establecer una sólida agenda diplomática con el resto de las naciones latinoamericanas se volvió un asunto de primer orden para el gobierno mexicano, tarea a la que se vieron abocados, desde los diarios constitucionalistas, hasta las más altas jerarquías en materia de relaciones exteriores. Como se pudo apreciar, incolucró también a los jóvenes intelectuales del movimiento estudiantil mexicano, que se unieron a la causa constitucionalista, proponiendo que se les integrara como parte del cuerpo diplomático de México en algunas naciones del sur del continente. De dicha propuesta resultó que se pusiera en marcha un programa de pensionados estudiantiles que representarían al gobierno mexicano en cinco legaciones mexicanas presentes en Suramérica, iniciativa que representa, en retrospectiva, el primer programa gubernamental de intercambio estudiantil de largo aliento en todo Latinoamérica.

BIBLIOGRAFÍA

SAlinas CARRANZA, AlBerTo, La expedición punitiva, México, Botas, 1937. ALtAMIRANO, CARlos, "Élites culturales en el siglo XX latinoamericano", en Carlos Altamirano [ed.], Historia de los Intelectuales en América Latina, Buenos Aires, Kats editores, 2008.

AstiÉ-Burgos, WalTER, Encuentros y desencuentros entre México y los Estados Unidos en el siglo XX. Del Porfiriato a la posguerra fría, México, Porrúa, 2007. 
El PAPEL del CONGRESO LOCAL ESTUDIANTIL EN LAS INICIATIVAS DE UNIDAD LATINOAMERICANA...

ARENAS GUZMÁN, DIEGO, El régimen del general Huerta en proyección bistórica, México, INEHRM, 1970.

BARRIOS, Miguel Ángel, El latinoamericanismo en el pensamiento politico de Manuel Ugarte, Buenos Aires, Biblios, 2007.

BARRÓn, LuIS, Carranza el último reformista porfiriano, México, Tusquets, 2009.

BASTIAN, JeAn-PIERRE, "Los propagandistas del constitucionalismo en México (1910-1920)", en Revista Mexicana de Sociología, vol. 45, núm. 2, 1983.

Bourdieu, Pierre, Intelectuales, política y poder, Buenos Aires, Eudeba, 1999.

CABRERA, Luis, La berencia de Carranza, México, INHERM, 2015.

CUMBERLAND, CHARLES, La Revolución mexicana. Los años constitucionalistas, México, FCE, 1980.

, Madero y la Revolución mexicana, México, Siglo XXI, MéxiCO, 1984.

FABELA, ISIDRO [ed.], Documentos históricos de la Revolución mexicana, México, Cámara de Senadores, LXI Legislatura/Universidad Autónoma Metropolitana, 2010.

Garciadiego, Javier y SANDra Kuntz Ficker, "La Revolución mexicana", en Nueva Historia general de México, México, El Colegio de México, 2014.

GARCIADIEGO, JaVIER, Autores, editoriales, instituciones y libros: estudios de historia intelectual, México, El Colegio de México, 2015.

Rudos contra científicos. La universidad nacional durante la Revolución mexicana, México, El Colegio de México/UnAm, 2000.

González Blanco, Pedro, De Porfirio Díaz a Carranza, México, Gobierno del Estado de Tabasco-Consejo Editorial, 1980.

Krauze, EnRique, Caudillos culturales en la Revolución mexicana, México, Siglo XXI, 1982.

LAJOUS, ROBERTA, Historia minima de las relaciones exteriores de México, 1821-2000, México, El Colegio de México, 2012.

LUQUIN, EDUARDO, La política internacional de la revolución constitucionalista, México, INEHRM, 1957. 
MÉNDEZ LARA, FRANCISCO IvÁN, "iVámonos para Veracruz! La prensa carrancista y su proyecto revolucionario: del puerto a la Ciudad de México (noviembre 1914-marzo 1915)", en Ulúa, núm. 24, Instituto de Investigaciones Histórico-Sociales de la Universidad Veracruzana, 2014.

Meyer, JeAn, De una revolución a la otra: México en la bistoria. Antología de textos, México, El Colegio de México, 2013.

, La Revolución mexicana, México, Tusquets, 2004.

NaVArRete Maya, Laura y Blanca Aguilar Plata, La prensa en México 18101915, México, Addison, 1998.

PalaCio MonTIEL, CElia DEL, "La prensa carrancista en Veracruz. 1915", en Folios, núm. 26, Antioquía, Universidad de Antioquía, 2011.

RAmos, Julio, Latinoamericanismo a contrapelo, Colombia, Universidad del Cauca, 2015.

ReED, Luis y María del CaRmen Ruíz Castañeda, El periodismo en México, 500 años de bistoria, México, Edamex, 1997.

Salinas Quiroga, Genaro, Los siete sabios de México, México, Universidad Autónoma de Nuevo León, 1980.

TORRES AgUILAR, MORELOS, Cultura y revolución. La universidad popular mexicana (Ciudad de México 1912-1920), México, unAM, 2009.

UGARTE MANuEL, La nación latinoamericana, Caracas, Biblioteca Ayacucho, 1978. vantes, 1922.

VelÁzQueZ AlBO, LOURDES, Los Congresos nacionales universitarios y los gobiernos de la Revolución 1910-1933, México, IISUE-UnAm/Plaza y Valdés, 2007.

YANKELEVICH, PABLo, "Una mirada argentina de la Revolución mexicana. La gesta de Manuel Ugarte (1910-1917)", en Historia Mexicana, vol. 44, núm. 4, México, abril-junio de 1995. 
El Papel del Congreso Local Estudiantil en las InIIIATIVAS de UNIDAd LATINOAMERICANA...

HEMEROGRAFÍA

Boletín de la Universidad

El Demócrata

El Monitor Republicano

El Pueblo

El Universal

Excélsior

Heraldo

La Lucha, Periódico de estudiantes

San Ev Ank, Revista semanaria estudiantil 
